\title{
POZZOLANIC ACTIVITY OF FLINT POWDER
}

\author{
Lennart Osterhus $^{1}$, Florian Ditz ${ }^{2}$, Frank Schmidt-Döhl ${ }^{3}$ \\ 1 TUHH B3, D 21071 Hamburg, lennart.osterhus@tuhh.de, University of \\ Technology Hamburg \\ 2 Richard Ditting GmbH \& Co. KG, Pinnasberg 45, D 20359 Hamburg, \\ florian.ditz@ditting-bau.de \\ 3 TUHH B3, D 21071 Hamburg, schmidt-doehl@tuhh.de, University of \\ Technology Hamburg
}

\begin{abstract}
It was tested whether powdered flint is able to reach pozzolanic properties comparable to fly ash. The flint aggregates were crushed and milled to three different grain size fractions comparable to coal fly ash. The powdered flint was characterized and subsequently used as a substitute in mortar prisms. The compressive strength tests showed a potentially pozzolanic reactive behavior at 28 days of two different fine grained flint fractions. But comparable investigations after 92 days showed that the typical subsequent hardening of pozzolanic materials could not be obtained. The strength was much lower than the strength of comparable specimens with fly ash. Further, thermogravimetric analysis of the tested mortars after 28 days showed a much lower portlandite consumption compared with mortar with fly ash. The study concludes that at least the examined powdered flint with high density does not have the opportunity to replace coal fly ash as pozzolan.
\end{abstract}

Keywords: Flint, fly ash, pozzolanic reaction, ASR, activity index

\section{INTRODUCTION}

Pozzolans are very important substances for the binder and concrete technology. Due to energy efficiency and the reduction of carbon dioxide emissions, portland cements are progressively displaced by pozzolan or composite cements. Apart from the energetic advantages pozzolanic additives may decrease the heat release rate, increase the tightness and, in the case of silica fume, also the strength of concrete notably. In Germany, coal fly ash is a very important pozzolan. It is a byproduct of the coal-based power generation. Due to ecological reasons this form of power generation might decrease. Therefore, coal fly ash will become less common and more expensive. 
There is a chemical analogy of the pozzolanic reaction and the alkali-silica-reaction (ASR), visible in the fact, that great agglomerates of silica fume will generate an ASR. The ASR is defined by the reaction between soluble silica from aggregates and alkali hydroxides in the concrete pore solution. The reaction product is an alkali-silica gel which enlarges its volume by water absorption and incorporates calcium further on. This formation can lead to expansion effects and crack generation which diminish the durability of a concrete. The pozzolanic activity is based on the reaction of $\mathrm{Ca}(\mathrm{OH})_{2}$ (portlandite) with fine grained reactive $\mathrm{SiO}_{2}$ to additional $\mathrm{C}-\mathrm{S}-\mathrm{H}$ phases. This leads to an improvement of concrete properties.

It seems a worthy subject of scientific study to evaluate the capability of powdered alkali-reactive aggregates as a pozzolanic additive to compensate the loss of coal fly ash. Especially, rapidly reactive aggregates, e.g. flint, attract wide interest as a pozzolan. For that reason a defined preparation of flint aggregates was realized. The powder was characterized in terms of particle size distribution, grain shape, specific surface and chemistry. Flint powder containing mortar prisms were examined to characterize the pozzolanic reactivity via activity index and the determined thermogravimetric $\mathrm{Ca}(\mathrm{OH})_{2}$-consumption in comparison to reference samples and mortar prisms with coal fly ash substitution. This was carried out by F. Ditz (2015).

\section{THEORETICAL BACKGROUND}

\section{Pozzolanic Reaction}

The pozzolanic reactivity increases the strength of cement-based building materials, due to chemical effects, like additional formation of C-S-H, as well as physical effects, like a better packing density. Furthermore, an improvement of workability (in the case of coal fly ash), durability and tightness can be obtained. At an early stage of hardening, the inclusion of alkalis in the low-calcium C-S-H phases is an advantage in regard to ASR prevention (Dressler, 2013). Pozzolans bind the available $\mathrm{Ca}^{2+}$ and the $\mathrm{C} / \mathrm{S}$ ratio decreases, proceeded by a stable incorporation of $\mathrm{Na}^{+}$and $\mathrm{K}^{+}$in the $\mathrm{C}-\mathrm{S}-\mathrm{H}$ phase. Pozzolans also prevent ASR due to their dense structure acting as filler and, therefore, cause a slow fluid and ion transportation within the building material. Decreasing capillary porosity means increasing concrete durability. However, pozzolans are able to decrease the amount of capillary porosity and increase the transport-inhibiting gel pores.

Several different pozzolanic additives exist presently in the industry often already as a byproduct in an established main production line. Silica fume is a byproduct of the production of ferrosilicon compounds with a high amount of amorphous $\mathrm{SiO}_{2}(>86$ wt.-\%). It is characterized by large specific surfaces $\left(\sim 20 \mathrm{~m}^{2} / \mathrm{g}\right)$ and small particle sizes $(0.1-0.3 \mu \mathrm{m})$. Due to these properties silica fume belongs to the fast reactive pozzolans with the ability to bond alkalis at the early hydration reaction. The reaction between silica fume and alkalis leads to the formation of an alkali-silica gel. This gel is able to incorporate $\mathrm{Ca}^{2+}$ which transforms to $\mathrm{C}-\mathrm{S}-\mathrm{H}$ phases. While silica fume shows silica contents of about 90 wt.-\% (Payá, J. et. al., 2002) coal fly ash represents a more 
heterogeneous pozzolanic additive with lower silica contents. Possibilities to use the former waste material of the coal-based power generation were evaluated since the beginning of the $20^{\text {th }}$ century (Stark \& Wicht, 2011). The chemical and physical properties of the coal fly ash strongly depend on the type of coal and the firing system which lead to the high heterogeneity of that material. The main components are $\mathrm{SiO}_{2}$, $\mathrm{Al}_{2} \mathrm{O}_{3}, \mathrm{Fe}_{2} \mathrm{O}_{3}$ and $\mathrm{CaO}$. European coal fly ashes usually show higher contents of $\mathrm{SiO}_{2}$, $\mathrm{Al}_{2} \mathrm{O}_{3}, \mathrm{Fe}_{2} \mathrm{O}_{3}$ and a lower content of $\mathrm{CaO}$. The lower the $\mathrm{CaO}$ content, the better the pozzolanic reactivity of a coal fly ash. A higher content of $\mathrm{CaO}$ would progressively lead to latent hydraulic reaction properties.

Influential for the pozzolanic reactivity is the amount of amorphous siliceous components. The solved silica reacts with the $\mathrm{Ca}(\mathrm{OH})_{2}$ to C-S-H phases. Al-rich coal fly ash leads to aluminum-bearing calciumsilicatehydrates (C-A-S-H). The reactivity of coal fly ash can be described by an activity index (DIN EN 450-1), based on mortar prism compressive strength tests.

\begin{abstract}
Alkali-Silica Reaction (ASR)
The ASR is a chemical reaction between solved $\mathrm{Si}$-species and the alkali hydroxides $(\mathrm{NaOH}, \mathrm{KOH})$ in the pore solution of the hardened concrete and from the outside. An alkali-silica reaction will not proceed when there is not enough solved $\mathrm{SiO}_{2}$, alkali hydroxides, and humidity. The reaction product is an alkali-silica gel building up a swelling pressure and incorporating calcium with time. Possible damages are expansion of the concrete structure and the formation of cracks. The alkali-silicareactivity depends on the kind, amount, reactivity and size of the alkali-sensitive aggregates. Also, the amount of alkali-hydroxides in the pore solution, humidity, and temperature conditions determine the process (Stark \& Wicht, 2013).
\end{abstract}

The reactivity of aggregates is tested in Germany according to the DAfStb (German Committee for Reinforced Concrete) alkali-guideline (DAfStb, 2013). Flint is an example for an aggregate which can lead to massive concrete damages due to alkalisilica reaction. In Germany the assessment of flint reactivity is based on the bulk density, calculating the portion of reactive flint. Flint consists of crypto- and microcrystalline $\mathrm{SiO}_{2}$ (chalcedon, cryptocrystalline quartz). Furthermore, flint can contain 1-3 vol.-\% amorphous silica (opal). Particularly flint with a bulk density $<2.2$ $\mathrm{Mg} / \mathrm{m}^{3}$ is very reactive (Stark \& Wicht, 2013).

Both, the pozzolanic reaction and the ASR show a reaction between solved silica from an aggregate, respectively an additive, and the alkalis of the pore solution. The main difference between both processes is the chemical kinetics. The pozzolanic reaction of the small particles begins directly after the formation of portlandite and finishes after several weeks. However, a cracking based on ASR often starts years or decades after the production of the concrete. Also only particles with a minimal size are able to produce cracks. This different kinetics has a big influence on the effect of the reaction type. While the ASR can result in a complete destruction of a building, the pozzolanic reaction may improve the properties of building materials. 


\section{MATERIALS AND METHODS}

\section{Materials}

The used cement was a portland cement CEM I $42.5 \mathrm{~N}$ according to DIN EN 197. As aggregates for the mortar production, CEN standard sand according to DIN EN 196-1 was used. For comparative investigations coal fly ash containing mortar prisms should be produced. Therefore, EFA Filler KM/C was used. The manufacturer guarantees an amount of 25 M.-\% reactive $\mathrm{SiO}_{2}$. As a potential replacement for fly ash, flint was collected from the Baltic Sea coast near Steinbeck, Germany.

First, the flint was crushed roughly with a sledgehammer. Inhomogeneous flint bodies, e.g. calcareous shells, were sorted out. Hereinafter, the flint was grinded with a jaw crusher. Inhomogeneous fragments were sorted out. The received material was split into three sections for different refined grinding. The flint fragments were grinded with a conventional planetary ball mill in steel vessels and three different grinding durations. One flint fraction was milled at $360 \mathrm{rpm}$ for 8 minutes (FL 8m). Another fraction was milled for 15 minutes (FL $15 \mathrm{~m}$ ) and the third one for 22 minutes (FL $22 \mathrm{~m}$ ). The different durations shall lead to different particle sizes and finally to different reaction behavior. Additionally, FL $22 \mathrm{~m}$ was sieved with a $90 \mu \mathrm{m}$ sieve at dry conditions.

\section{Particle Size Distribution}

The particle size distribution was measured via laser diffraction with a Mastersizer 3000 from Malvern. The dispersion liquid was ethanol, the solid concentration was between 0.14 and $0.16 \%$. The samples were stirred with $3500 \mathrm{rpm}$ and ultrasound. Before the measurement the ultrasound was deactivated and the speed was reduced piecewise to $1700 \mathrm{rpm}$. Measurements were analyzed with the Mie-theory. The refractive index was assumed to be 1.65 .

\section{Grain Shape}

The flint powders and the coal fly ash were investigated by microscopic techniques. Dispersions with flint powders respectively coal fly ash and distilled water were examined with a polarization microscope $\mathrm{D} 2500 \mathrm{P}$ from Leica in transmitted light. The precise procedure is described by Wittern (2014) and Ditz (2015). The grain shape was described by the ratios of the three main axes and the rounding as well as the sphericity of the particles. The classification referred to the ratios between the three main axes follows the principle of Zingg described by Tucker (1985). The different geometries are chips, fibres and granules. The description of the rounding and sphericity follows the principle of Pettijohn described by Tucker (1985). There are six rounding classes with more or less sphericity. 50 particles of each powder fraction and the coal fly ash were characterized. However, the measurement of the depth was unreliable. Therefore, the length and width should match for the investigation of grain geometries. 


\section{Bulk Density}

The bulk density was determined according to DIN EN 1097-6. Aggregates were measured in a wire basket. Flint fragments were stored under water for one week. Afterwards, the aggregates were weighed in a wire basket under water. The flint fragments were dried with a wipe until there was subtle surface moisture. At this condition, aggregates were weighed again. Then, the fragments were dried in an oven at $105^{\circ} \mathrm{C}$ for five days to the constant mass and subsequently weighed once more.

\section{Specific Surface}

The specific surface area was investigated by the BET method with $\mathrm{N}_{2}$-sorption (Micromeritics ASAP 2010). The measurement errors are assumed to be about $10 \%$.

\section{Chemical Composition}

The chemical composition was measured with a X-ray fluorescence spectrometer (Horiba XGT 7200). The excitation voltage was $30 \mathrm{kV}$ and the diameter of the capillary tube was $1.2 \mathrm{~mm}$. FL $22 \mathrm{~m}$ and the coal fly ash were measured in air. The data were analyzed with the fundamental parameter method and normalized to 100 percent. As standard the cement NIST 1881a was used.

\section{Thermoanalysis}

Thermogravimetry was performed with a STA $449 \mathrm{C}$ from Netzsch. The prisms of the 28 days mortar were pulverized and measured in the range between 20 and $1100{ }^{\circ} \mathrm{C}$. The heating rate was $10 \mathrm{~K} / \mathrm{min}$ under argon atmosphere.

\section{Activity Index}

The production of mortar prisms followed DIN EN 196-1. The composition for the reference mortar contains $450 \mathrm{~g}$ CEM I $42.5 \mathrm{~N}, 1350 \mathrm{~g}$ CEN standard sand and $225 \mathrm{~g}$ water. Therefore, a w/c ratio of 0.5 was adjusted. $25 \mathrm{wt} .-\%$ of the cement of the prisms with flint and coal fly ash was substituted with these additives. Thus, $75 \mathrm{wt} .-\%$ cement remained in these compositions and the $\mathrm{w} / \mathrm{b}$ ratio was 0.5 . Compaction was realized by vibration. The consistency was measured as flow spread. After 24 hours, the formwork was stripped and the prisms were stored under water for 27 respectively 91 days more.

The testing for compressive strength was realized according to DIN EN 196-1 after 28 and 92 days. The compressive strength was used for the determination of the activity index. This index gives information about the strength of a mortar with substitution of cement, in this case fly ash or flint. The compressive strength is compared with the strength of mortar prisms without substitution. In the case of fly ash, the activity index has to reach $75 \%$ of the compressive strength of the reference mortar without pozzolanic substitution after 28 days. After 90 days, the activity index has to reach $85 \%$. 


\section{RESULTS AND DISCUSSION}

\section{Characterization of Materials}

The particle size distributions are given in table 1 and figure 1 . The differences in curve shapes are minimal, but distinguishable. The long-milled flint FL 22m has smaller particles as FL 8m. In comparison to the flint powders the fly ash has larger grains. The grain shapes are given in table 2 .

Table 1. Results of particle size distributions. FL - flint, FA - fly ash. (Ditz, 2015)

\begin{tabular}{|l|l|l|l|l|}
\hline & FL 8m & FL 15m & FL 22m & FA \\
\hline $\mathrm{d}_{10}[\mu \mathrm{m}]$ & 1.91 & 1.24 & 0.98 & 3.39 \\
\hline $\mathrm{d}_{50}[\mu \mathrm{m}]$ & 14.50 & 9.92 & 7.68 & 14.50 \\
\hline $\mathrm{d}_{90}[\mu \mathrm{m}]$ & 53.3 & 35.8 & 28.4 & 66.5 \\
\hline peak pos. $1[\mu \mathrm{m}]$ & 0.70 & 0.60 & 0.60 & 0.45 \\
\hline peak pos. $2[\mu \mathrm{m}]$ & 3.0 & 3.0 & 3.0 & 13.0 \\
\hline peak pos. $3[\mu \mathrm{m}]$ & 25.0 & 21.0 & 20.0 & 60.0 \\
\hline
\end{tabular}

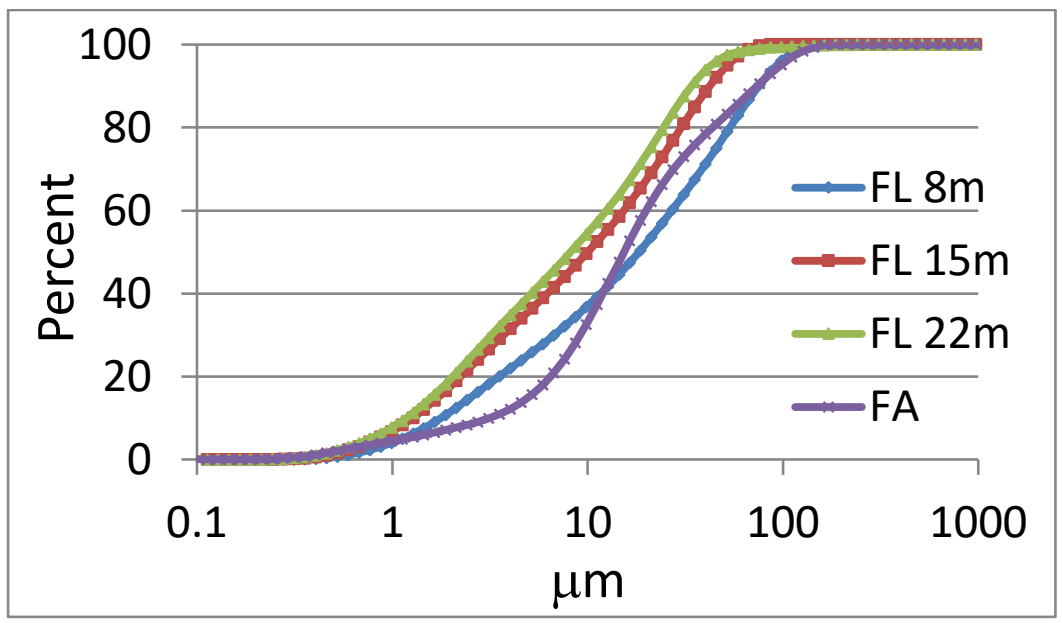

Figure 1. Results of particle size distributions. FL - flint, FA - fly ash.

The grain shape studies show significant differences between the milled flint particles and coal fly ash. Latter has a characteristic spherical shape with partial cracked shell fragments. The flint particles show different shapes and are correlated with the grinding duration. FL $8 \mathrm{~m}$ and FL $22 \mathrm{~m}$ have a lower sphericity compared to FL $15 \mathrm{~m}$. Therefore, the milling process seems to influence the grain shape less while the rounding is directly proportional to the length of the grinding process (figure $2 \mathrm{a}-\mathrm{d}$ ). 
Table 2. Grain shapes. FL - flint, FA - fly ash.

\begin{tabular}{|c|c|c|c|c|}
\hline & FL 8m & FL $15 \mathrm{~m}$ & FL $22 \mathrm{~m}$ & FA \\
\hline & {$[\%]$} & {$[\%]$} & {$[\%]$} & {$[\%]$} \\
\hline \multicolumn{5}{|c|}{$\begin{array}{l}\text { Rounding: } 0=\text { very edgy, } 1=\text { edgy, } 2=\text { edgy with weak rounded shapes } \\
3=\text { rounded off, } 4=\text { rounded, } 5=\text { well rounded }\end{array}$} \\
\hline 0 & 0 & 0 & 0 & 0 \\
\hline 1 & 18 & 4 & 0 & 0 \\
\hline 2 & 58 & 40 & 16 & 0 \\
\hline 3 & 24 & 48 & 70 & 0 \\
\hline 4 & 0 & 8 & 14 & 0 \\
\hline 5 & 0 & 0 & 0 & 100 \\
\hline \multicolumn{5}{|c|}{ Sphericity } \\
\hline low & 66 & 54 & 68 & 0 \\
\hline high & 34 & 46 & 32 & 100 \\
\hline \multicolumn{5}{|c|}{ b/a axial ratio } \\
\hline$>0.66$ & 62 & 66 & 74 & 100 \\
\hline$<0.66$ & 38 & 34 & 26 & 0 \\
\hline
\end{tabular}
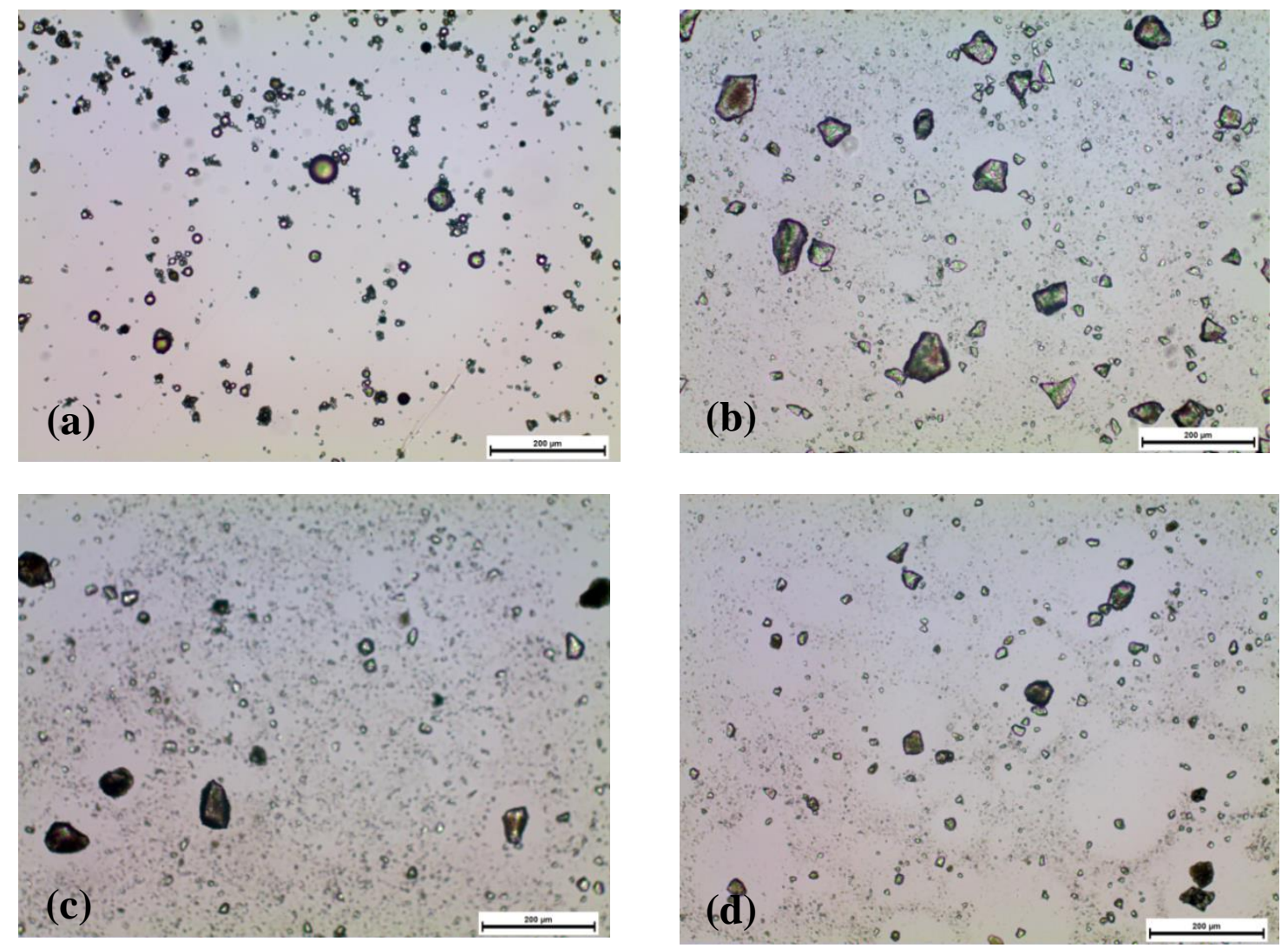

Figure 2. Microscopic images of the different grain shapes and sizes of (a) FA, (b) FL $8 \mathrm{~m}$, (c) FL 15m and (d) FL 22m. The scale corresponds to $200 \mu \mathrm{m}$. 
The bulk density of the flint is $\rho=2.6 \mathrm{Mg} / \mathrm{m}^{3}$. This value implies only a very weak reactivity according to the German ASR guideline (DAfStb, 2013). The specific surface of the flint powder varies with the milling duration. FL $8 \mathrm{~m}$ has a specific surface of $3.10 \mathrm{~m}^{2} / \mathrm{g}$, FL $15 \mathrm{~m}$ of $5.54 \mathrm{~m}^{2} / \mathrm{g}$ and the finest material FL $22 \mathrm{~m}$ shows a specific surface of $6.69 \mathrm{~m}^{2} / \mathrm{g}$. The differences are small, but the tendency is visible.

The chemical composition was measured for FL $22 \mathrm{~m}$ and the fly ash (table 3). FL $22 \mathrm{~m}$ has a high $\mathrm{SiO}_{2}$-content of approx. 97 wt.- $\%$ and low contents of $\mathrm{MgO}, \mathrm{Na}_{2} \mathrm{O}, \mathrm{SO}_{3}$, $\mathrm{CaO}$ and $\mathrm{Cr}_{2} \mathrm{O}_{3}$. The coal fly ash shows a more heterogeneous composition with approx. 50 wt.- $\% \mathrm{SiO}_{2}, 24$ wt.- $\% \mathrm{Al}_{2} \mathrm{O}_{3}, 10$ wt.- $\% \mathrm{Fe}_{2} \mathrm{O}_{3}$ total, 5 wt.- $\% \mathrm{~K}_{2} \mathrm{O}$ and 6.6 wt.$\% \mathrm{CaO}$.

Table 3. Chemical composition of flint FL $22 \mathrm{~m}$ and coal fly ash FL, n.d. = not detectable. (Ditz, 2015)

\begin{tabular}{|l|l|l|}
\hline & FL 22m [wt.-\%] & FA [wt.-\%] \\
\hline $\mathrm{Na}_{2} \mathrm{O}$ & 0.06 & 0.05 \\
\hline $\mathrm{MgO}$ & 0.50 & 0.96 \\
\hline $\mathrm{Al}_{2} \mathrm{O}_{3}$ & n.d. & 24.28 \\
\hline $\mathrm{SiO}_{2}$ & 97.42 & 49.73 \\
\hline $\mathrm{SO}_{3}$ & 0.07 & 1.07 \\
\hline $\mathrm{K}_{2} \mathrm{O}$ & n.d. & 5.06 \\
\hline $\mathrm{CaO}$ & 0.23 & 6.63 \\
\hline $\mathrm{TiO}_{2}$ & n.d. & 1.60 \\
\hline $\mathrm{Cr}_{2} \mathrm{O}_{3}$ & 0.16 & 0.03 \\
\hline $\mathrm{MnO}_{2}$ & n.d. & 0.15 \\
\hline $\mathrm{Fe}{ }_{2} \mathrm{O}_{3}$ total & 1.55 & 10.18 \\
\hline $\mathrm{ZnO}$ & n.d. & 0.19 \\
\hline $\mathrm{SrO}$ & n.d. & 0.07 \\
\hline
\end{tabular}

During the preparation of the mortar prisms, the flow spread was measured. Results are given in table 4 . The results show strong similarities between the reference and the flint substituted mortars $(163-177 \mathrm{~mm})$. Solely, the flow spread of the mortars with fly ash is significant larger (193-196mm). While the usage of flint does not show to have an influence on the workability of the fresh mortar, the use of fly ash leads to a positive effect. This is due to the special morphology of fly ash particles (see figure $2 \mathrm{a}$ ).

\section{Pozzolanic Activity}

Results of the compressive strength tests after 28 and 92 days are given in table 5 . After 28 days, the reference sample R $28 \mathrm{~d}$ shows the highest compressive strength. FL $22 \mathrm{~m} 28 \mathrm{~d}$ shows the highest compressive strength of all substituted samples, with similar properties as the fly ash. The compressive strength of the flint substituted samples increases with increasing grinding time of the flint, suggesting that the particle size of the flint powder has a large influence on the mortar compressive strength. The activity indices show that only FL $8 \mathrm{~m} 28 \mathrm{~d}$ is not able to reach the limit of $75 \%$ after 28 days (DIN EN 450-1). This effect is not necessarily related to a pozzolanic 
reactivity. Also the filler effect could affect these measured values (Huettl, 2000). After 92 days, the activity indices of the mortars with flint are nearly constant compared to 28 days. The mortar with fly ash shows a major change to an increased value of $96.3 \%$. However, the limit for pozzolanic reactivity of fly ashes is $85 \%$ after 90 days (DIN EN 450-1). This value is not achieved by the flint substituted samples.

Table 4. Flow spread of fresh mortar for reference samples $\mathrm{R}$ and samples with 28 and 92 days storage time, FL- flint, FA - fly ash. (Ditz, 2015)

\begin{tabular}{|l|l|}
\hline Sample & $\begin{array}{l}\text { Flow spread } \\
{[\mathrm{mm}]}\end{array}$ \\
\hline R 28d & $165 / 166$ \\
\hline R 91d & $170 / 170$ \\
\hline FL 8m 28d & $172 / 172$ \\
\hline FL 8m 92d & $168 / 170$ \\
\hline FL 15m 28d & $163 / 164$ \\
\hline FL 15m 92d & $172 / 173$ \\
\hline FL 22m 28d & $172 / 177$ \\
\hline FL 22m 92d & $172 / 175$ \\
\hline FA 28d & $196 / 196$ \\
\hline FA 92d & $193 / 195$ \\
\hline
\end{tabular}

Table 5. Compressive strength test and activity indices after 28 and 92 days, R reference mortar, FL- flint, FA -fly ash.

\begin{tabular}{|l|l|l|}
\hline Sample & $\begin{array}{l}\text { Compressive strength } \\
{[\mathrm{MPa}]}\end{array}$ & Activity index [\%] \\
\hline R 28d & 60.73 & 100.0 \\
\hline FL 8m 28d & 42.98 & 70.8 \\
\hline FL 15m 28d & 46.60 & 76.7 \\
\hline FL 22m 28d & 47.97 & 79.0 \\
\hline FA 28d & 47.55 & 78.3 \\
\hline R 92d & 68.40 & 100.0 \\
\hline FL 8m 92d & 49.80 & 72.8 \\
\hline FL 15m 92d & 52.50 & 76.8 \\
\hline FL 22m 92d & 54.10 & 79.1 \\
\hline FA 92d & 65.90 & 96.3 \\
\hline
\end{tabular}

To support the conclusion that the flint substituted mortar samples might show no noticeable pozzolanic reactivity, thermogravimetric measurements with the grinded mortar fragments after the compressive strength test were performed. Here, the weight loss between 370 and $580^{\circ} \mathrm{C}$ of cement-based materials can be matched to the decomposition of $\mathrm{Ca}(\mathrm{OH})_{2}$. In addition the mass changes by drying, decomposition of C-S-H and other phases like AFm and AFt and decomposition of carbonate must be considered (Taylor, 1997, Marsh \& Day, 1988, Pane \& Hanson, 2005). Thus, it can be calculated how much $\mathrm{Ca}(\mathrm{OH})_{2}$ was initially in the mortar sample and how much was consumed during the hardening process over 28 days. To give a better comparison, the 
mass change of the reference sample R $28 \mathrm{~d}$ was equalized to $100 \%$. The results are given in figure 3 .

It has to be considered that substitution of $25 \mathrm{wt} .-\%$ of the cement with additives also leads to a significant lower amount of $75 \mathrm{wt} .-\% \mathrm{Ca}(\mathrm{OH})_{2}$ remaining in the mortar. Therefore, one can assume that values considerably below $75 \%$ related to the not substituted reference sample could show $\mathrm{Ca}(\mathrm{OH})_{2}$-reduction due to pozzolanic reactivity. While FL $8 \mathrm{~m} \mathrm{28d}(82.6 \%)$ and FL $15 \mathrm{~m} 28 \mathrm{~d}(79.3 \%)$ do not indicate portlandite-reduction, FA 28d shows significant reduction $(60.9 \%)$. The sample FL $22 \mathrm{~m} 28 \mathrm{~d}$ shows a relative mass change to $68.5 \%$. Here, a low influence of $\mathrm{Ca}(\mathrm{OH})_{2}-$ consumption could be suggested.

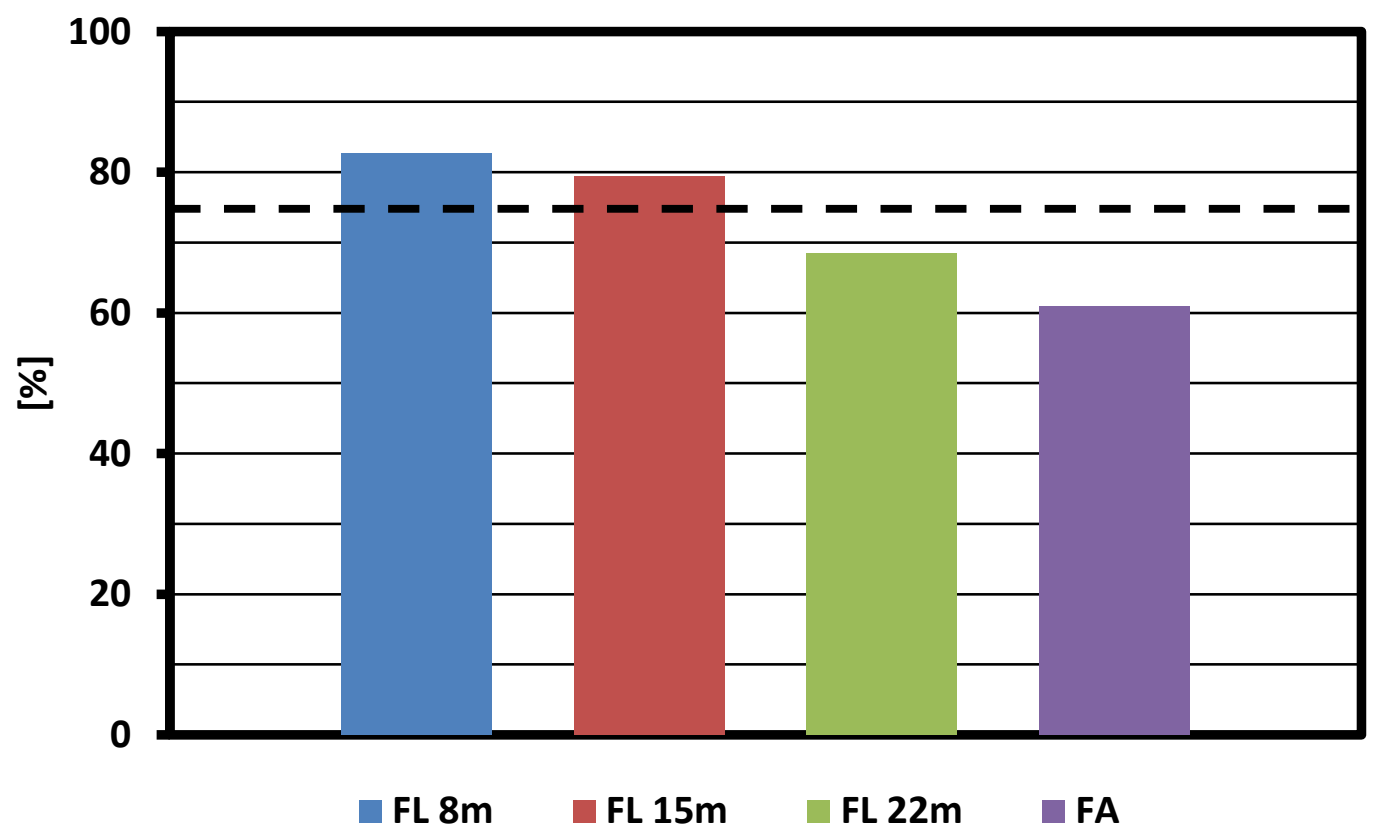

Figure 3. Results of thermogravimetric measurements from 28 days old mortar samples. The lower the percent, the higher the $\mathrm{Ca}(\mathrm{OH})_{2}$-consumption. $100 \%$ is the value of the reference mortar without addition. The limit on $75 \%$ marks the reduction of the total $\mathrm{Ca}(\mathrm{OH})_{2}$-content due to $25 \%$ substitution with additives. An increased portlandite-consumption has to show values below this limit. (Ditz, 2015)

\section{CONCLUSIONS}

As to be expected there is a relation between milling duration and particle size of the flint powders. The longer the milling process, the finer the powder. The results also show that reached particle sizes are in the range of coal fly ash particles and smaller. The grain shape of the sharp-edged pulverized flint particles strongly differentiates from the spherical coal fly ash granules. 
The workability of the flint powder substituted fresh mortar is unaffected. In contrast, the usage of coal fly ash as a substitute leads to considerably improved fresh mortar properties. While the activity indices of FL $15 \mathrm{~m}$, FL $22 \mathrm{~m}$ and FA after 28 days are higher than the $75 \%$ limit, the coarsest FL $8 \mathrm{~m}$ is not able to reach this limit value. After 92 days, only the coal fly ash exceeds the limit of $85 \%$ for the activity index. From the other samples, FL $22 \mathrm{~m}$ shows the best results with $\sim 80 \%$. However, the subsequent hardening beyond 28 days of the flint substituted mortars was generally lower. In the case, the flint powders initiate a pozzolanic reaction, it is significant lower than the reactivity of the coal fly ash. The good results of the 28 days compressive strength tests may be a result of an increased filler effect. However, thermogravimetric investigations display that only the coal fly ash substituted mortar shows remarkable pozzolanic behavior by an increased consumption of $\mathrm{Ca}(\mathrm{OH})_{2}$.

To sum up, the examined flint with high density is no adequate replacement for coal fly ash. However, further strength enhancement can be obtained. This effect is probably traced back to the filler effect and not to pozzolanic reactivity of the flint powders.

\section{REFERENCES}

DAfStb (2013-10). Richtlinie Vorbeugende Maßnahmen gegen schädigende Alkalireaktion im Beton (Alkali-Richtlinie), Beuth, Berlin.

DIN EN 196-1 (2016-11). Methods of testing cement - Part 1: Determination of strength, Beuth, Berlin.

DIN EN 197-1 (2011-11). Cement - Part 1: Composition, specifications and conformity criteria for common cements, Beuth, Berlin.

DIN EN 450-1 (2012-12). Fly ash for concrete - Part 1: Definition, specifications and conformity criteria, Beuth, Berlin.

DIN EN 1097-6 (2013-9). Tests for mechanical and physical properties of aggregates - Part 6: Determination of particle density and water absorption, Beuth, Berlin.

Ditz, F. (2015). Puzzolane aus neuen, alternativen Materialien als Ersatz für Steinkohlenflugasche, Bachelorthesis, Technische Universität HamburgHarburg.

Dressler, A. (2013). Einfluss von Tausalz und puzzolanischen, aluminiumhaltigen Zusatzstoffen auf die Mechanismen einer schädigenden Alkali-KieselsäureReaktion in Beton, Dissertation, Technische Universität München.

Huettl, R. (2000). Der Wirkungsmechanismus von Steinkohlenflugasche als Betonzusatzstoff, Dissertation, Technische Universität Berlin.

Marsh, B.K. and Day, R.L. (1988). "Pozzolanic and cementitious reactions of flyash in blended cement pastes." Cem Concr Res, 18(2), 301-310.

Pane, I. and Hansen, W. (2005). "Investigation of blended cement hydration by isothermal calorimetry and thermal analysis." Cem Concr Res, 35(6), 11551164. 
Payá, J., Monzó, J., Borrachero, M.V., Amahjour, F., Girbés, I., Velázques, S., Ordóñez, L.M. (2002). "Advantages in the use of fly ashes in cements containing pozzolanic combustion residues: silica fume, sewage sludge ash, spent fluidized bed catalyst and rice husk ash." Chem Tech Biotech, 77(3), 331335.

Stark, J. and Wicht, B. (2011). Geschichte der Baustoffe, Bauverlag, Wiesbaden Berlin.

Stark, J. and Wicht, B. (2013). Dauerhaftigkeit von Beton, 2. ed., Springer Vieweg, Berlin, Heidelberg.

Taylor, H.F.W. (1997). Cement chemistry, 2. ed., Thomas Telford, London.

Tucker, E.M. (1985). Einführung in die Sedimentpetrologie, Ferdinand Enke Verlag, Stuttgart.

Wittern, M. (2014). Korngrößenverteilung und -untersuchung mittels Lasergranulometrie, Bachelorthesis, Technische Universität HamburgHarburg. 